\title{
Coléteres dendróides em Alibertia sessilis (Vell.) K. Schum., uma espécie não-nodulada de Rubiaceae ${ }^{1}$
}

\author{
DANIELA PACHECO BARREIRO ${ }^{2}$ e SILVIA RODRIGUES MACHADO ${ }^{2,3}$
}

(recebido: 2 de março de 2006; aceito: 21 de junho de 2007)

\begin{abstract}
Dendroid colleters of Alibertia sessilis (Vell.) K. Schum., a non-nodulated Rubiaceae species). This paper describes the distribution, structure and histochemistry of the colleters in vegetative and reproductive apices of Alibertia sessilis (Vell.) K. Schum., a native Rubiaceae species of the Brazilian “cerrado". In this family, dendroid colleters have been associated with the presence of bacterial nodules in the leaves. Samples were prepared according to common light and scanning electron microscopy techniques, and histochemical assays involved freshly collected material. Colleters are dendroid and occur on the adaxial surface of stipules, bracts and sepals; they consist of a multicellular and multiseriate central axis of parenchymatous nature, covered by digitiform or sharply pointed epidermal cells of irregular sizes, joined together only in the proximal portion and separated from each other in the distal portion. The columnar cells are axially elongated, with thick cell walls, prominent nucleus and reduced cytoplasm, developed vacuole with lipid inclusions and phenolic compounds. The epidermal cells have thin walls, a conspicuous nucleus, abundant cytoplasm and a poorly developed vacuome. The colleters are devoid of cuticle. The secretion is more abundant in the vegetative apex, impregnating the leaf buds and the stipules, forming a spherical cap that is hard, bright, and hydrophobic. In all analyzed samples, the histochemical assays detected polysaccharides, proteins and lipids in the protoplast of both epidermal and columnar cells; phenolic compounds were detected solely in the columnar cells. The resinous nature of the exudate was confirmed with the use of the diethylic ether solvent. Bacterial leaf nodules were not found.
\end{abstract}

Key words - Alibertia sessilis, anatomy, dendroid colleters, histochemistry, Rubiaceae

RESUMO - (Coléteres dendróides em Alibertia sessilis (Vell.) K. Schum., uma espécie não-nodulada de Rubiaceae). Este trabalho descreve a distribuição, estrutura e histoquímica dos coléteres presentes em ápices vegetativo e reprodutivo de Alibertia sessilis (Vell.) K. Schum., uma espécie de Rubiaceae nativa do cerrado. Coléteres dendróides, nesta família, têm sido freqüentemente associados com a presença de nódulos bacterianos nas folhas. As amostras foram preparadas segundo técnicas usuais em microscopia de luz e eletrônica de varredura. Testes histoquímicos foram feitos em secções de material recém coletado. Os coléteres são do tipo dendróide e ocorrem na face adaxial das estípulas, brácteas e sépalas; consistem de um eixo central multicelular e multisseriado, de natureza parenquimática, revestido por células epidérmicas digitiformes ou pontiagudas de tamanhos irregulares, unidas entre si somente na porção proximal e separadas umas das outras na porção distal. As células colunares são axialmente alongadas e possuem paredes espessas, núcleo conspícuo, citoplasma reduzido, vacúolo desenvolvido com acúmulo de lipídeos e substâncias fenólicas. As células epidérmicas possuem paredes delgadas, núcleo conspícuo, citoplasma abundante e vacuoma pouco desenvolvido. Os coléteres não possuem cutícula. A secreção é mais abundante no ápice vegetativo, impregnando os primórdios foliares e as estípulas, formando uma capa esférica dura, brilhante e hidrofóbica. Em todas as amostras analisadas, os testes histoquímicos detectaram polissacarídeos, proteínas e lipídeos no protoplasto de células colunares e epidérmicas; compostos fenólicos foram detectados unicamente nas células colunares. A natureza resinosa do exsudato foi confirmada com o uso do solvente éter dietílico. Não foram encontrados nódulos bacterianos nas folhas.

Palavras-chave - Alibertia sessilis, anatomia, coléteres dendróides, histoquímica, Rubiaceae

\section{Introdução}

Coléteres são estruturas glandulares encontradas na superfície adaxial de órgãos reprodutivos e/ou

\footnotetext{
1. Parte da dissertação de mestrado do primeiro autor, Programa de Pós-Graduação em Ciências Biológicas (Botânica), Universidade Estadual Paulista, Instituto de Biociências, Câmpus de Botucatu.

2. Universidade Estadual Paulista, Instituto de Biociências, Departamento de Botânica, Caixa Postal 510, 18618-000, Botucatu, SP, Brasil.

3. Autor para correspondência: smachado@ibb.unesp.br
}

vegetativos jovens de um grande número de famílias (Thomas 1991). A função principal da secreção produzida por coléteres relaciona-se com a proteção de meristemas e órgãos em desenvolvimento, sendo estes lubrificados e protegidos contra dessecação, herbívoros e patógenos (Thomas et al. 1989, Thomas \& Dave 1989a, b, Thomas 1991). O que diferencia os coléteres das demais estruturas secretoras é a composição do exsudato que pode ser constituída unicamente por mucilagem (Fahn 1979, Thomas 1991) ou uma mistura de mucilagem e substâncias lipofílicas (Fahn 1979, 1990, KronestedtRobards \& Robards 1991). 
Em Rubiaceae, os coléteres ocorrem principalmente na superfície adaxial de estípulas (Solereder 1908, Horner \& Lersten 1968, Van Hove 1972, Lersten 1974a, Thomas 1991), podendo ser encontrados em pecíolos (Johansson 1987), cálice (Robbrecht 1987, Dave et al. 1988), brácteas, bractéolas e corola (Thomas \& Dave 1989c). Em sua extensa revisão, Thomas (1991) incluiu seis tipos de coléteres descritos para a família Rubiaceae: padrão, padrão-reduzido, dendróide, escova, alado e filiforme sendo que o número, a morfologia e o arranjo dessas estruturas são elementos relevantes para determinações taxonômicas e filogenéticas (Woodson \& Moore 1938, Jayaweera 1963a, b, 1964, 1965, Lersten 1974a, b, 1975, Aiello 1979, Thomas \& Dave 1990). Coléter dendróide, com raras exceções, tem sido associado a espécies com nódulos bacterianos foliares e está presente em vários gêneros de Rubiaceae, incluindo Alibertia A. Rich. ex DC. (Lersten 1975, Thomas 1991). No caso das espécies com nódulos bacterianos foliares, o exsudato liberado pelos coléteres além de constituir uma fonte nutritiva contribui para a entrada das bactérias no mesofilo, via estômatos (Lersten \& Horner 1967).

Alibertia sessilis (Vell.) K. Schum., conhecida como "marmelinho" ou "marmelo-do-cerrado", é uma espécie subarbustiva de grande importância alimentícia e medicinal (Guarim Neto 1985, Rodrigues \& Carvalho 2001). Os frutos desta espécie são consumidos ao natural ou utilizados na forma de geléias e tortas pela população; suas folhas são consumidas por bovinos e junto com seus ramos são utilizadas em preparações medicinais, como compressa, banho e cataplasma, na cura de afecções da pele (Almeida et al. 1998). Em literatura, não foram encontradas referências sobre coléteres para esta espécie.

Este trabalho descreve pela primeira vez a ocorrência de coléteres dendróides em ápices reprodutivo e vegetativo de $A$. sessilis, com informações sobre sua morfologia, anatomia e histoquímica.

\section{Material e métodos}

Ápices reprodutivo e vegetativo foram coletados de exemplares de A. sessilis crescendo em fragmentos de cerrado

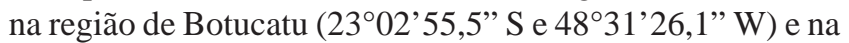
Reserva Particular da Fazenda Palmeira da Serra, Município de Pratânia (2248'50,2” S e 4844’35, $8^{\prime}$ 'W), Estado de São Paulo, Brasil. Exsicatas foram depositadas no Herbário Irina Delanova Gemtchujnicov da Universidade Estadual Paulista (UNESP), sob o número de registro BOTU 24406.

Estudo anatômico - Para análise geral da distribuição e estrutura dos coléteres, ápices intactos e suas partes dissecadas sob microscópio estereoscópico com o auxílio de estiletes foram fixados em solução de Karnovsky (paraformaldeído 4\%; glutaraldeído $1 \%$ em tampão fosfato $0,1 \mathrm{M} \mathrm{pH} 7,2$; tampão fosfato 0,2 M pH 7,2) por 24 horas (Karnovsky 1965). Posteriormente, o material foi desidratado em série crescente de soluções de álcool e embebido em historresina (Gerrits 1991). Secções (6-8 $\mu \mathrm{m}$ de espessura) foram obtidas em micrótomo de rotação semi-automático e coradas com azul de toluidina 0,05\% pH 4,7 (O’Brien et al. 1965). Lâminas permanentes foram montadas em resina sintética (Gerlach 1969), observadas e documentadas em Fotomicroscópio Leica DMR. A contagem do número de células foi realizada em secções transversais e longitudinais de coléteres de ápices vegetativos $(n=30)$.

Para verificar a ocorrência de nódulos bacterianos, folhas em diferentes estágios de desenvolvimento foram cuidadosamente examinadas ao microscópio estereoscópico; posteriormente, amostras retiradas dos terços basal, mediano e distal do limbo dessas folhas foram seccionadas transversalmente com auxílio de micrótomo de Ranvier. As secções, sem coloração, foram montadas em glicerina e examinadas ao microscópio de luz. Histoquímica - Para detectar as principais classes de metabólitos nas células dos coléteres, secções de material recém coletado, não fixado, obtidas à mão livre com auxílio de micrótomo de Ranvier foram tratadas com: (a) Sudan IV para lipídeos em geral (Pearse 1980); (b) ácido periódico/Reagente de Schiff (PAS) para polissacarídeos neutros (Cortelazzo 1992); (c) vermelho de rutênio para polissacarídeos diversos (Jensen 1962); (d) cloreto férrico para compostos fenólicos (Johansen 1940); (e) solução de azul mercúrio de bromofenol para proteínas (Mazia et al. 1953); (f) ácido sulfúrico a 10\% para cristais de oxalato de cálcio (Johansen 1940). Os cortes foram montados entre lâmina e lamínula utilizando-se glicerina como meio de montagem e analisados imediatamente. Tratamento controle foi conduzido simultaneamente para cada teste realizado, segundo indicado pelos respectivos autores acima referidos. Microscopia Eletrônica de Varredura (MEV) - Estípulas, brácteas e sépalas foram fixadas como descrito acima, pós-fixadas em tetróxido de ósmio $1 \%$ em tampão fosfato $0,1 \mathrm{M} \mathrm{pH}$ 7,3 por 1 hora, desidratadas em série crescente de soluções de álcool, submetidas ao sistema de secagem em ponto crítico CPD 020 (Balzer Union) utilizando-se $\mathrm{CO}_{2}$ líquido, montadas em suportes de alumínio e metalizadas com ouro. As amostras foram observadas e documentadas ao microscópio eletrônico de varredura (MEV) Philips SEM 515, a 20 kV.

Extração do exsudato para observação ao MEV - A abundância e a consistência da secreção dificultaram as observações e a obtenção de imagens dos coléteres ao microscópio eletrônico de varredura. Assim, foram testados diferentes solventes indicados para extração de secreções (Ramayya \& Bahadur 1968, Durkee et al. 1984, Subramanian et al. 1989, Thomas \& Dave 1990). Amostras de ápices vegetativo e reprodutivo foram coletadas e, com a ajuda de estiletes sob estereomicroscópio, foram destacadas as estípulas, brácteas e sépalas. Em seguida, estas estruturas foram imersas em frascos de penicilina contendo os seguintes solventes: acetona, água acética $1 \%$, água destilada, álcool etílico, benzeno e éter dietílico. Os frascos permaneceram à temperatura ambiente, em tempos variáveis de 10 segundos a 10 minutos. Frascos de penicilina contendo 
estípulas, brácteas e sépalas imersas em água destilada foram também levados à estufa a $60^{\circ} \mathrm{C}$, durante 30 minutos. A seguir, com o auxílio de um pincel de poucas cerdas, o exsudato foi sendo cuidadosamente removido. Subseqüentemente, as amostras foram lavadas com água destilada, fixadas em solução de Karnovsky (Karnovsky 1965) por 24 horas e processadas segundo a técnica descrita para MEV.

\section{Resultados}

O ápice vegetativo, no período do brotamento, é protegido por estípulas verdes intumescidas recobertas por uma capa esférica de uma substância esbranquiçada, hidrofóbica e de aspecto perolado (figura 1). Esta substância acumula-se gradualmente na parte interna das estípulas e, quando extravasa para a superfície do ápice, torna-se vítrea e quebradiça (figuras 2-4). No período em que o ápice está dormente, as estípulas possuem aspecto ressecado, de coloração marrom escuro e não apresentam acúmulo de secreção (figura 5).

Os coléteres começam a secretar antes da expansão dos primórdios foliares e florais, aos quais eles estão ligados. O exsudato é um material pegajoso, abundante, que cobre completamente as estruturas em desenvolvimento (figura 6) e se solidifica em contato com o ar (figuras 1-4). Estípulas, brácteas e sépalas apresentam coléteres na superfície adaxial (figuras 6-7), cuja coloração varia de amarelo-palha a marrom ou parda (figura 7).

O ápice reprodutivo, no início do seu desenvolvimento (figura 8), apresenta-se totalmente recoberto por secreção hialina, hidrofóbica e pouco abundante em comparação com o ápice vegetativo. Secreção de aspecto semelhante é observada na superfície de cada botão floral da inflorescência (figura 9).

Os coléteres apresentam-se total ou parcialmente recobertos pela secreção (figuras 10), o que dificulta a sua visualização.

Os tratamentos com álcool e benzeno, por 10 minutos, dissolveram a secreção presente na superfície das estípulas, brácteas e sépalas, mas não a extraíram da superfície dos coléteres (figuras 11-12). Com benzeno, houve colapso generalizado das células dos coléteres (figura 13). Tratamento com éter dietílico, por 30 segundos, dissolveu a secreção sem danos às células e permitiu a observação da distribuição, estrutura e a classificação dos coléteres (figuras 14-20).

Nas estípulas (figura 14), os coléteres estão distribuídos em várias fileiras ao redor dos primórdios foliares; são mais abundantes na base, podendo ocorrer de modo esparso por toda a superfície adaxial da estípula; atingem $700 \mu \mathrm{m}$ de comprimento. Nas brácteas (figura 15), os coléteres localizam-se desde a base até o seu terço médio e distribuem-se em várias camadas ao redor dos primórdios florais. Nas sépalas (figura 16), os coléteres estão concentrados na base, em camada única. Nas brácteas e sépalas, os coléteres atingem comprimentos que variam de 650 a $680 \mu \mathrm{m}$.

Em todas as amostras analisadas ao MEV, os coléteres são coniformes e consistem de um eixo com inúmeras células alongadas, de tamanhos variáveis, com disposição antrorsa (figuras 17-18). As células são cilíndricas, pontiagudas (figura 17) ou digitiformes (figura 19), ocorrendo, também, células com abaulamentos pronunciados na sua base, região mediana ou no ápice (figura 20). A superfície das células é lisa ou levemente estriada, apresentando grumos ou flocos (figuras 19-20) que correspondem a restos da secreção.

Os coléteres são mais abundantes no ápice vegetativo (figuras 21,23) em comparação com o ápice reprodutivo (figuras 25-26). Consistem de um eixo central multicelular e multisseriado, com 30-40 células de altura, em secção longitudinal (figuras 21-22), e cerca de 20-50 células parenquimáticas volumosas, em secção transversal (figuras 23-24). Este eixo é revestido por cerca de 90-110 células epidérmicas dispostas em camada única (figura 24). As células epidérmicas possuem tamanhos irregulares (figuras 22, 24), sendo unidas entre si apenas em sua porção proximal e separadas umas das outras em sua porção distal. O número de células epidérmicas aparentemente é maior nos coléteres do ápice reprodutivo (figura 27), enquanto que a secreção é mais abundante no ápice vegetativo.

As células do eixo central são axialmente alongadas e possuem parede pectocelulósica espessa, núcleo volumoso, citoplasma reduzido e vacúolos desenvolvidos. As células epidérmicas apresentam paredes delgadas, núcleo volumoso e citoplasma abundante (figuras 22,27). Em todas as amostras analisadas, verificou-se que os coléteres não apresentam cutícula.

Coléteres presentes em estípulas, brácteas e sépalas mostraram reação positiva para compostos fenólicos, lipídeos, polissacarídeos e proteínas. Compostos fenólicos foram observados unicamente nas células colunares, cujo conteúdo foi intensamente corado de verde pelo azul de toluidina (figura 28); lipídeos (figura 29), polissacarídeos (figura 30) e proteínas (figura 31) foram detectados em todas as células dos coléteres, sendo a intensidade de reação variável entre as células colunares e epidérmicas. Cristais de oxalato de cálcio do tipo drusa foram freqüentemente observados nas células colunares, sendo sua frequiência maior nos coléteres estipulares.

Em A. sessilis não foram observados nódulos bacterianos nas folhas. 

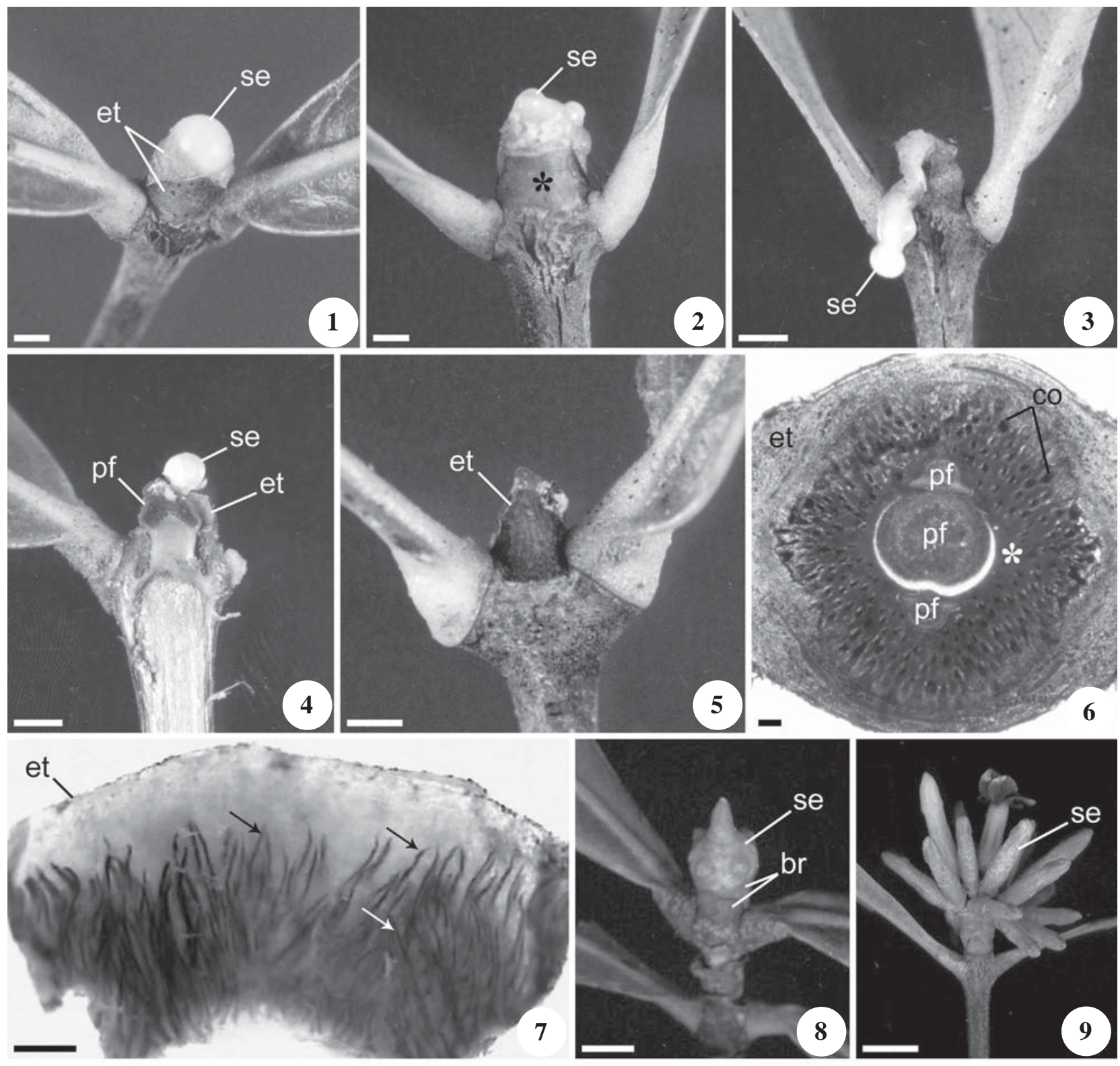

Figuras 1-9. Ápices vegetativos e reprodutivos de Alibertia sessilis. 1. Ápice de ramo vegetativo mostrando estípulas recobertas por secreção resinosa. 2. Ápice vegetativo com uma estípula removida (*) mostrando acúmulos de secreção. 3. Ápice vegetativo, mostrando secreção abundante. 4. Ápice vegetativo cortado longitudinalmente, mostrando estípula, secreção perolada e primórdios foliares. 5. Ápice vegetativo dormente com estípulas ressecadas, sem acúmulo de secreção. 6. Secção transversal de ápice vegetativo mostrando a disposição dos coléteres na superfície adaxial da estípula e primórdios foliares imersos na secreção $(*)$. 7. Estípula removida mostrando coléteres (setas) em fileiras na superfície adaxial. 8. Inflorescência em início de desenvolvimento com secreção de aspecto vítreo. 9. Secreção na superfície de botões florais. $($ br $=$ brácteas; $c o=$ coléteres; et = estípulas; $p f=$ primórdios foliares; se $=$ secreção). Barras $=3 \mathrm{~cm}(1,5), 3,3 \mathrm{~cm}(2,4), 2 \mathrm{~cm}(3), 250 \mu \mathrm{m}(6), 7 \mathrm{~cm}(7), 2,5 \mathrm{~cm}(8), 1,2 \mathrm{~cm}(9)$.

Figures 1-9. Vegetative and reproductive apices of Alibertia sessilis. 1. Vegetative apex with stipules covered by resinous secretion. 2. Vegetative apex, stipule was removed $(*)$, showing accumulation of viscous secretion. 3. Vegetative apex with abundant secretion. 4. Vegetative apex cut longitudinally showing stipule, pearly secretion and leaf buds. 5. Vegetative apex in dormancy with dried out stipules, without secretion. 6. Cross-section of vegetative apex showing the arrangement of the colleters on the adaxial surface of the stipule and bud leaves submerged in the secretion $(*)$. 7. Removed stipule showing colleters (arrows) in rows at the adaxial surface. 8. Young inflorescence with vitreous secretion. 9. Secretion in the floral bud surfaces. $(\mathrm{br}=$ bracts; $\mathrm{co}=$ colleters; et $=$ stipules; $\mathrm{pf}=$ leaf buds; $\mathrm{se}=$ secretion). $\mathrm{Bars}=3 \mathrm{~cm}(1,5), 3,3 \mathrm{~cm}(2,4), 2 \mathrm{~cm}(3), 250$ $\mathrm{mm}(6), 7 \mathrm{~cm}(7), 2,5 \mathrm{~cm}(8), 1,2 \mathrm{~cm}(9)$. 

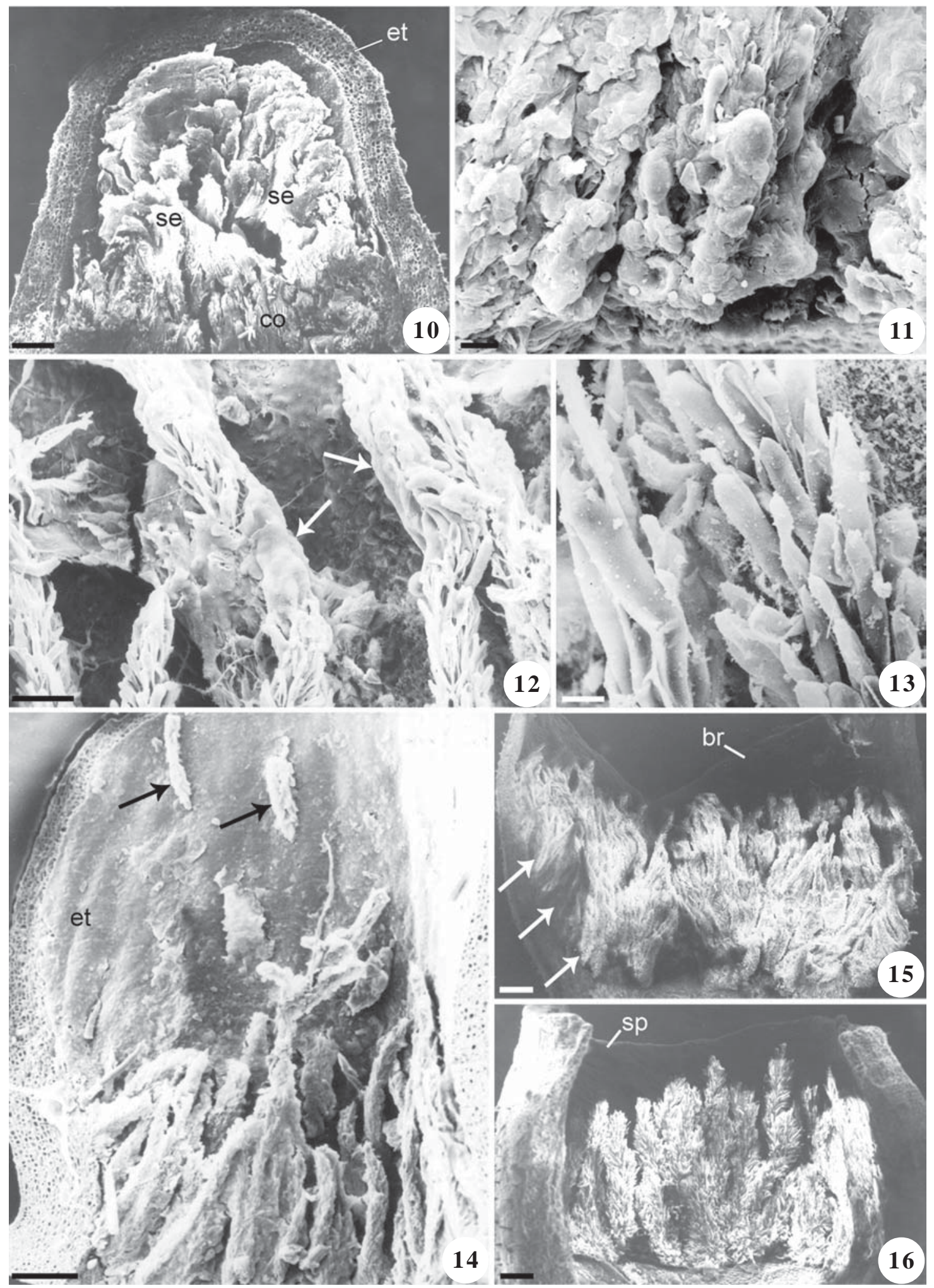

Figuras 10-16. Ápices vegetativos e reprodutivos de Alibertia sessilis (MEV). 10. Estípula com acúmulo de secreção, dificultando a observação dos coléteres. 11-12. Coléteres parcial ou totalmente cobertos por secreção (setas). 13. Células colapsadas devido ao tratamento com benzeno. 14. Coléteres arranjados em fileiras na base da superfície adaxial da estípula, sendo que alguns se localizam de maneira esparsa (setas). 15. Coléteres dispostos em fileiras (setas) na superfície adaxial da bráctea. 16. Coléteres localizados na base de sépala, na superfície adaxial. $(\mathrm{br}=$ brácteas; $c o=$ coléteres; et $=$ estípulas; $\mathrm{se}=$ secreção; $\mathrm{sp}$ = sépala). Barras = $135 \mu \mathrm{m}$ (10), $24 \mu \mathrm{m}$ (11), $35 \mu \mathrm{m}$ (12), $10 \mu \mathrm{m}$ (13), $195 \mu \mathrm{m}$ (14), $210 \mu \mathrm{m}$ (15), $105 \mu \mathrm{m}(16)$. 


\section{Discussão}

Plantas de Alibertia sessilis apresentam coléteres na superfície adaxial de estípulas, brácteas e sépalas, conforme observado em outras espécies de Rubiaceae (Robbrecht 1978, 1983, Dave et al. 1988). Tais coléteres não são vascularizados e se caracterizam por apresentar um eixo central multicelular alongado, de natureza parenquimática, revestido por inúmeras células epidérmicas que são parcialmente ou totalmente separadas umas das outras, conferindo aos coléteres um aspecto ramificado. Os coléteres observados em A. sessilis enquadram-se no tipo dendróide, conforme denominação de Lersten (1974a, b).

Os coléteres dendróides em A. sessilis possuem cerca de $700 \mu \mathrm{m}$ e, portanto, são considerados de tamanho médio, segundo classificação proposta por Lersten (1975). Este autor realizou um vasto estudo sobre coléteres em Rubiaceae de diferentes procedências e observou diferenças consideráveis com relação ao tamanho dessas estruturas que provavelmente estariam associadas com a distribuição geográfica das plantas. Coléteres de tamanho médio $(783 \mu \mathrm{m})$ foram encontrados nos neotrópicos, sendo que em espécies de Psychotria da América do Sul a maioria dos coléteres possui tamanho igual ou superior a $2.600 \mu \mathrm{m}$. Lersten (1975) relatou que o tamanho médio diminui em direção Oeste a partir da Oceania (735 $\mu \mathrm{m})$, Filipinas $(553 \mu \mathrm{m})$, Índias do Leste e Austrália $(480 \mu \mathrm{m})$, Ásia $(410 \mu \mathrm{m})$ e África $(334 \mu \mathrm{m})$, sendo este último com tamanho cerca de $40 \%$ do encontrado nas Américas Central e do Sul.

Os coléteres começam a secretar precocemente, antes mesmo da expansão dos primórdios foliares e florais. A solidificação da secreção, inicialmente pegajosa, quando em contato com o ar, indica sua natureza resinosa (Langenheim 2003). A mudança da coloração dos coléteres dendróides de amarelo-palha para marrom ou parda, conforme observado em $A$. sessilis, foi igualmente relatada para diferentes espécies e está relacionada com a parada da atividade secretora e início do processo de senescência dos mesmos (Thomas \& Dave 1990, Thomas 1991, Appezzato-da-Glória \& Estelita 2000).

Os testes histoquímicos usados neste trabalho permitiram detectar a presença de compostos fenólicos, lipídeos, polissacarídeos e proteínas em coléteres de estípulas, brácteas e sépalas. A presença dessas substâncias, isoladamente ou em misturas complexas, foi igualmente detectada em coléteres de diferentes taxa (Horner \& Lersten 1968, Thomas \& Dave 1989b, Thomas et al. 1989, Thomas \& Dave 1990, Appezzatoda-Glória \& Estelita 2000, Klein et al. 2004). Secreção resinosa e acúmulo de lipídeos foram observados em células epidérmicas dos coléteres de Gardenia gummifera (Mangalan et al. 1990).

$\mathrm{O}$ exsudato presente na superfície dos coléteres de ápices vegetativo e reprodutivo de A. sessilis foi extraído unicamente com éter dietílico, o que, segundo alguns autores, indica a natureza resinosa da secreção (Subramanian et al. 1989). Produção de resina em coléteres tem sido referida para certos gêneros de Rubiaceae (Solereder 1908, Fahn 1979, Langenheim 2003). Segundo Langenheim (2003), resinas na superfície de estípulas (que protegem os primórdios foliares), folhas jovens, caules jovens e/ou cálice floral, em geral são constituídas por uma mistura complexa de terpenos e flavonóides lipofílicos que se solidificam a temperatura ambiente. Segundo o autor, essas substâncias são comuns em plantas crescendo em ambientes diversos; em regiões áridas e semi-áridas, têm sido associadas com proteção dos tecidos em desenvolvimento contra dessecação e predação; em ambientes tropicais úmidos, a resina protege contra a grande diversidade de insetos fitófagos, mamíferos e microorganismos patogênicos que são abundantes nesses ambientes. Krause (1909, apud Langenheim 2003) observou que nas espécies de Gardenia habitando ambientes áridos a resina produzida por coléteres estipulares diminuía a transpiração, enquanto espécies de ambientes úmidos não apresentavam coléteres. Resinas contendo terpenos voláteis ou compostos fenólicos também podem atrair parasitóides ou predadores dos herbívoros que atacam a planta, promovendo uma defesa indireta (Langenheim 2003). De modo similar ao observado em $A$. sessilis, em algumas espécies de Dalechampia as resinas são à prova de água e produzidas regular e previsivelmente; no caso das resinas florais, tais substâncias constituem um recurso particularmente valioso para as abelhas fêmeas que as utilizam na construção do ninho. Ainda com relação a

Figures 10-16. Vegetative and reproductive apices of Alibertia sessilis (SEM). 10. Stipule with secretion. 11-12. Colleters partially or totally covered by secretion (arrows). 13. Collapsed cells due to benzene treatment. 14. Colleters in rows at the base of the stipule's adaxial surface, some are scattered over the surface (arrows). Colleters lined up in rows (arrows) on the bract's adaxial surface. 16 . Colleters located at the base of sepal, on the adaxial surface. $(\mathrm{br}=$ bracts; $c o=$ colleters; et $=$ stipules; se $=$ secretion; sp = sepal). Bars = $135 \mu \mathrm{m}$ (10), $24 \mu \mathrm{m}$ (11), $35 \mu \mathrm{m}$ (12), $10 \mu \mathrm{m}$ (13), $195 \mu \mathrm{m}$ (14), $210 \mu \mathrm{m}$ (15), $105 \mu \mathrm{m}$ (16). 


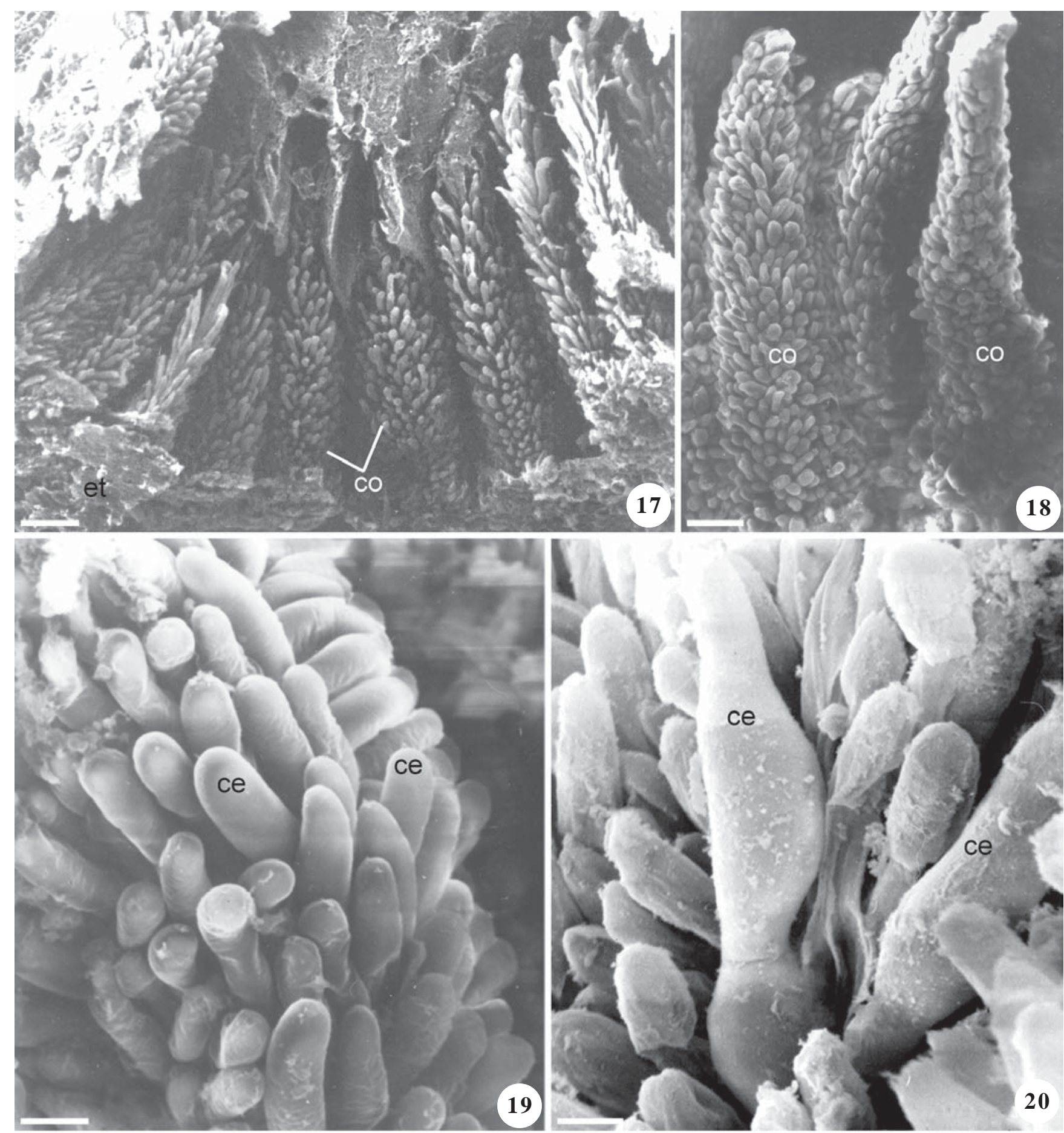

Figuras 17-20. Coléteres dendróides de Alibertia sessilis (MEV). 17. Estípula tratada com éter dietílico, evidenciando os coléteres. 18. Coléteres dendróides em brácteas tratadas com éter dietílico. 19. Detalhe mostrando células epidérmicas cilíndricas digitiformes. 20. Células epidérmicas com abaulamentos pronunciados, mostrando grumos de secreção em sua superfície. (ce $=$ células epidérmicas; $c 0=$ coléteres; et = estípulas). Barras = $60 \mu \mathrm{m}(17), 40 \mu \mathrm{m}(18), 10 \mu \mathrm{m}(19), 5 \mu \mathrm{m}(20)$.

Figures 17-20. Dendroid colleters of Alibertia sessilis (SEM). 17. Stipule treated with diethyl ether evidencing the colleters. 18. Dendroid colleters on bracts treated with diethyl ether. 19. Detail showing cylindrical digitiform epidermal cells. 20. Epidermal cells with pronounced cambers showing secretion grumes on their surfaces. $(\mathrm{ce}=$ epidermal cells; $\mathrm{co}=\mathrm{colleters}$; et $=$ stipules $)$. Bars $=60 \mu \mathrm{m}(17), 40 \mu \mathrm{m}(18), 10 \mu \mathrm{m}(19), 5 \mu \mathrm{m}(20)$. 

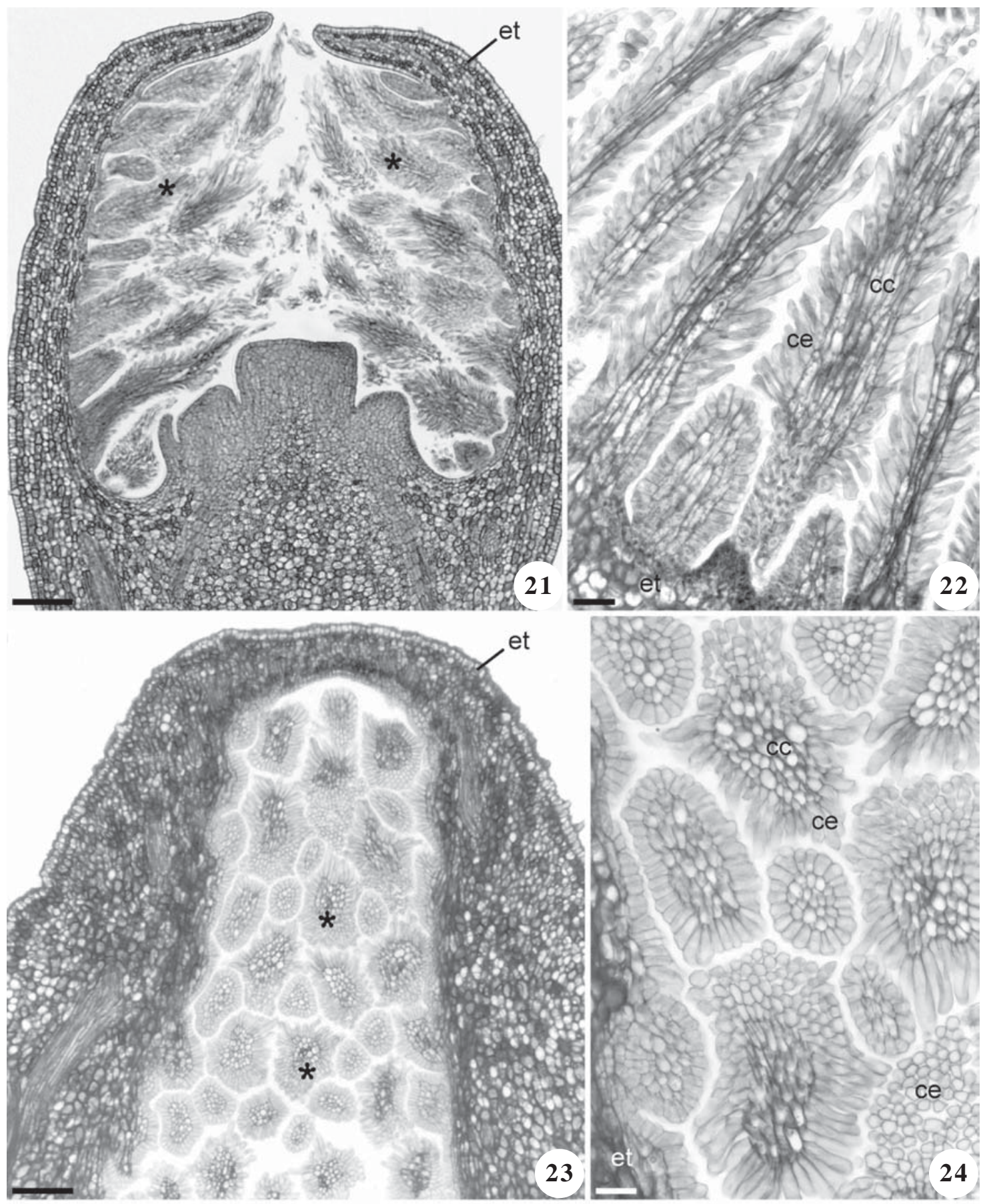

Figuras 21-24. Coléteres dendróides estipulares de Alibertia sessilis (microscopia de luz). 21. Secção longitudinal do ápice vegetativo mostrando a disposição dos coléteres $\left(^{*}\right)$ na superfície adaxial das estípulas. 22 . Detalhe evidenciando a estrutura dos coléteres estipulares com células colunares e epidérmicas. 23. Secção transversal de ápice vegetativo, mostrando a disposição e estrutura dos coléteres (*). 24. Detalhe evidenciando coléteres com numerosas células colunares e células epidérmicas dispostas em camada única. ( $c c=$ células colunares; $c e=$ células epidérmicas; et $=$ estípulas). Barras $=110 \mu \mathrm{m}(21)$, $25 \mu \mathrm{m}(22), 85 \mu \mathrm{m}(23), 20 \mu \mathrm{m}(24)$.

Figures 21-24. Stipular dendroid colleters of Alibertia sessilis (light microscopy). 21. Longitudinal section of the vegetative apex showing the arrangement of the colleters $(*)$ on the adaxial surface of the stipules. 22. Detail showing the structure of the stipular colleters with columnar and epidermal cells. 23. Cross-section of vegetative apex showing the arrangement and structure of the colleters $(*)$. 24. Detail evidencing colleters with numerous columnar cells and epidermal cells arranged in a single layer. (cc = columnar cells; $c e=$ epidermal cells; et = stipules). Bars $=110 \mu \mathrm{m}(21), 25 \mu \mathrm{m}(22), 85 \mu \mathrm{m}(23), 20 \mu \mathrm{m}(24)$. 

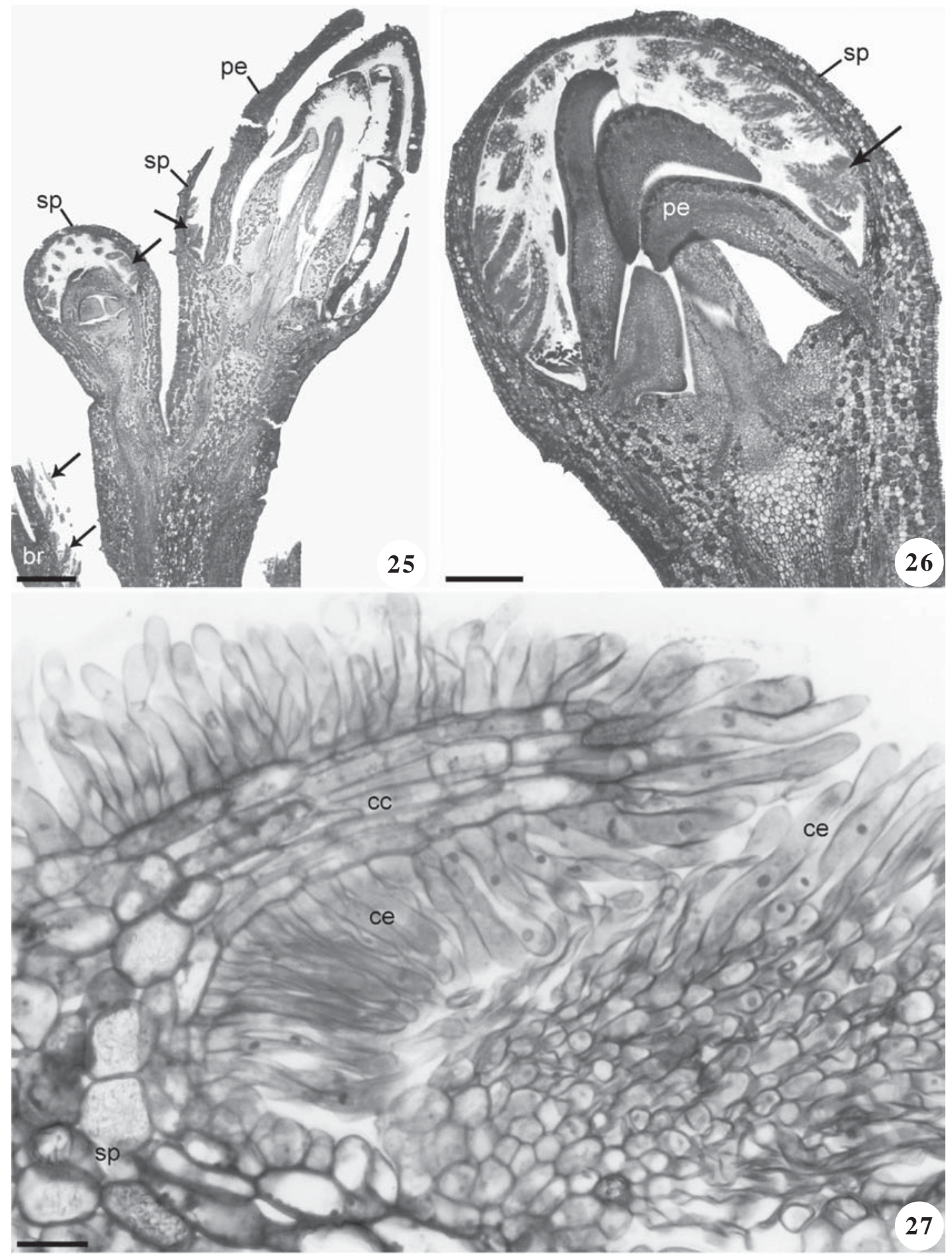

Figuras 25-27. Coléteres dendróides em brácteas e sépalas de Alibertia sessilis (microscopia de luz). 25. Secção longitudinal mediana de inflorescência em início do desenvolvimento evidenciando a disposição dos coléteres (setas) nas brácteas e nas sépalas. 26. Secção longitudinal de um botão floral, mostrando a disposição dos coléteres (seta) nas sépalas. 27. Coléteres dendróides de sépalas, mostrando células colunares e epidérmicas. $(\mathrm{br}=$ brácteas; $\mathrm{cc}=$ células colunares; $\mathrm{ce}=$ células epidérmicas; $\mathrm{pe}=$ pétalas; $\mathrm{sp}=$ sépalas). Barras $=200 \mu \mathrm{m}(25), 100 \mu \mathrm{m}(26), 20 \mu \mathrm{m}$ (27).

Figures 25-27. Dendroid colleters of bracts and sepals of Alibertia sessilis (light microscopy). 25. Longitudinal median section of incipient inflorescence evidencing the arrangement of the colleters (arrows) on the bracts and sepals. 26. Longitudinal section of floral buds showing the arrangement of the colleters (arrow) on the sepals. 27. Dendroid colleters of sepals showing columnar and epidermal cells. $(\mathrm{br}=$ bracts; $c c=$ columnar cells; $c e=$ epidermal cells; $\mathrm{pe}=$ petals; $\mathrm{sp}=$ sepals). Bars = $200 \mu \mathrm{m}(25), 100 \mu \mathrm{m}(26), 20 \mu \mathrm{m}(27)$. 

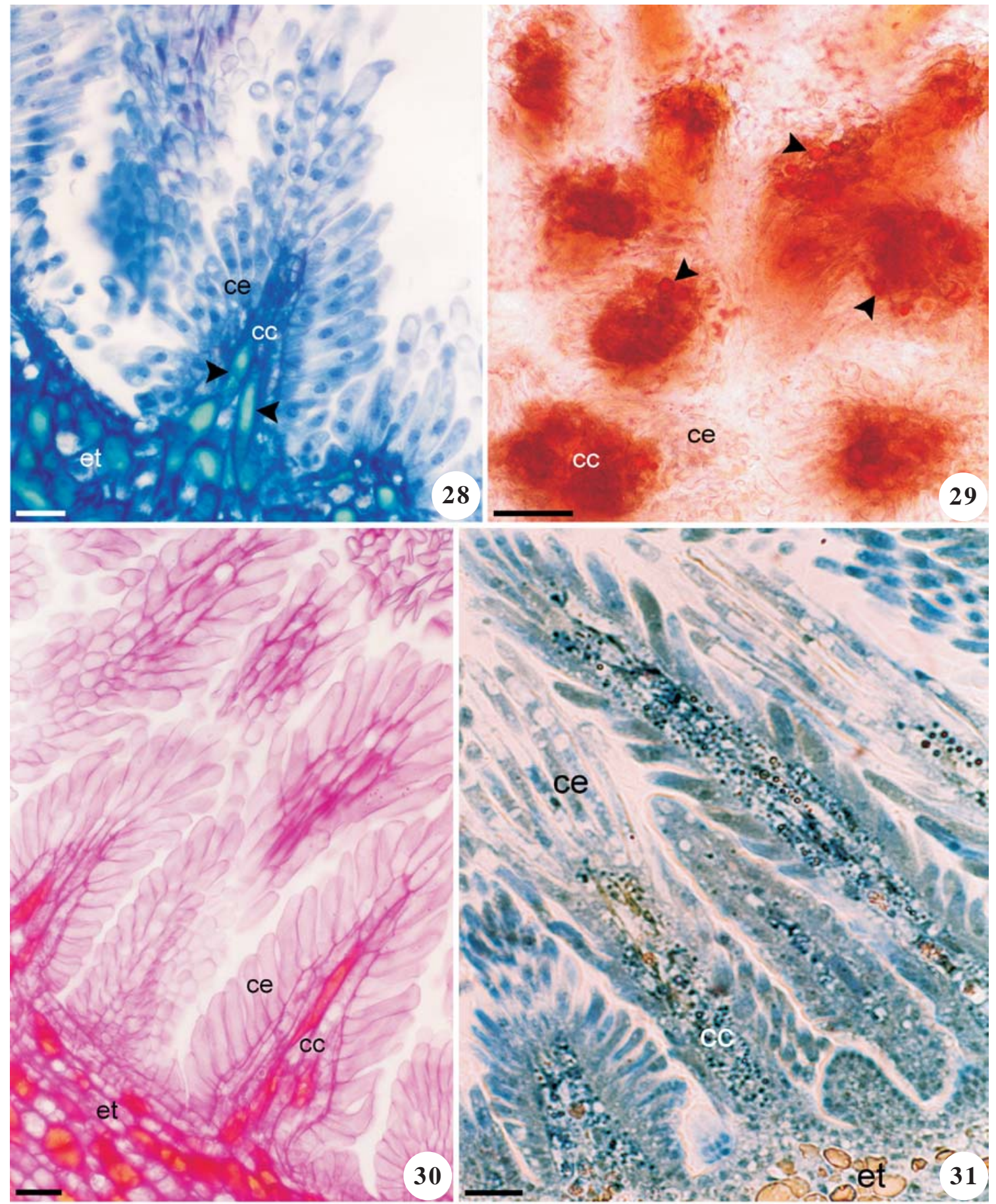

Figuras 28-31. Coléteres dendróides estipulares de Alibertia sessilis (microscopia de luz). 28. Células colunares com conteúdo denso (pontas de seta) corado de verde, indicando a presença de compostos fenólicos. 29. Teste com Sudan IV indicando a presença de lipídeos (pontas de seta). 30. Teste com PAS indicando a presença de polissacarídeos. 31. Teste com azul mercúrio de bromofenol, mostrando grânulos proteicos. $(\mathrm{cc}=$ células colunares; $\mathrm{ce}=$ células epidérmicas; et $=$ estípula $)$. Barras $=20 \mu \mathrm{m}$ $(28,30), 35 \mu \mathrm{m}(29), 30 \mu \mathrm{m}(31)$.

Figures 28-31. Stipular dendroid colleters of Alibertia sessilis (light microscopy). 28. Columnar cells with dense content (arrow heads) stained green, indicating the presence of phenolic compounds. 29. Assay with Sudan IV demonstrating the presence of lipids (arrow heads). 30. Assay with PAS indicating the presence of polysaccharides. 31. Assay with mercury-bromophenol blue, showing the presence of proteins visible as granules. $(\mathrm{cc}=$ columnar cells; $\mathrm{ce}=$ epidermal cells; et $=$ stipule $)$. Bars $=20 \mu \mathrm{m}$ $(28,30), 35 \mu \mathrm{m}(29), 30 \mu \mathrm{m}(31)$. 
essas plantas, as resinas contêm terpenos voláteis que atraem abelhas que utilizam tais substâncias como precursoras para feromônios sexuais (Armbruster 1993).

No presente trabalho, a falta de observações das plantas no campo e o desconhecimento da composição química da resina não permitem concluir sobre o papel da secreção produzida pelos coléteres dendróides nas interações planta-ambiente. Contudo, com base em literatura, é possível fazer algumas suposições. A produção de exsudato hidrofóbico nos coléteres de $A$. sessilis durante todo o período de crescimento vegetativo e de formação dos órgãos florais é particularmente significante nas condições do cerrado e, provavelmente, desempenha papel importante na proteção do tecido meristemático em desenvolvimento contra dessecação, herbívoros, patógenos e insetos (Dell 1977, Thomas et al. 1989, Thomas \& Dave 1990, Farrell et al. 1991, Thomas 1991, Zalucki et al. 2001, Cruz et al. 2002). Segundo Franco (2002), o cerrado caracteriza-se por apresentar clima sazonal com uma estação seca bem definida, com altas temperaturas e elevada intensidade luminosa, sendo que as plantas apresentam diferentes mecanismos de adaptação às condições climáticas deste ecossistema.

Embora neste trabalho a produção de exsudato não tenha sido quantificada, as diferenças visuais observadas na quantidade de material presente nos ápices vegetativo e reprodutivo podem estar relacionadas às condições climáticas do cerrado nas épocas de brotamento e floração, pois, segundo Langenheim (1994), fatores abióticos como intensidade luminosa e condições de umidade podem afetar a quantidade total de resina produzida pelas estruturas secretoras externas.

Em espécies de rubiáceas noduladas, a secreção dos coléteres é mucilaginosa e pode servir como via para as bactérias penetrarem nas folhas ainda muito jovens (Lersten \& Horner 1967, Miller et al. 1983), além de desempenhar papel vital na nutrição dessas bactérias simbióticas (Van Hove \& Kagoyre 1974, Lersten 1975, Miller et al. 1983). Em A. sessilis a secreção é resinosa e forma uma capa rígida e hidrofóbica em torno do ápice vegetativo. Este fato poderia explicar a ausência de nódulos bacterianos nas folhas.

Agradecimentos - À Fundação de Amparo à Pesquisa do Estado de São Paulo (FAPESP), pelas bolsas de Treinamento Técnico (Processo 02/09369-2) e Mestrado (Processo 03/11747-8) à primeira autora, e ao auxílio financeiro ao Projeto temático Processo 00/12469-3 (Programa-Biota); ao Conselho Nacional de Desenvolvimento Científico e Tecnológico (CNPq 302431/ 2002-0), pela bolsa de produtividade à S. R. Machado e ao Centro de Microscopia Eletrônica, Instituto de Biociências, UNESP, Câmpus de Botucatu, pela assistência técnica.

\section{Referências bibliográficas}

AIELLO, A. 1979. A reexamination of Portlandia (Rubiaceae) and associated taxa. Journal of Arnold Arboretum 60:38-123.

ALMEIDA, S.P., PROENÇA, C.E.B., SANO, S.M. \& RIBEIRO, J.F. 1998. Cerrado: espécies vegetais úteis. Embrapa-CPAC, Planaltina.

ARMBRUSTER, W.S. 1993. Evolution of plant pollination systems: hypotheses and tests with the Neotropical vine Dalechampia. Evolution 47:1480-1505.

APPEZZATO-DA-GLÓRIA, B. \& ESTELITA, M.E.M. 2000. Development, structure and distribution of colleters in Mandevilla illustris and M. Velutina (Apocynaceae). Revista Brasileira de Botânica 23:113-120.

CORTELAZZO, A.L. 1992. Detecção e quantificação do amido em cotilédones de Canavalia ensiformis e C. gladiata durante o desenvolvimento inicial da planta. Revista Brasileira de Botânica 15:157-162.

CRUZ,M.A.L., GOMES, V.M.,MACHADO,O.L.T.,FERNANDES, K.V.S. \& XAVIER FILHO, J. 2002. Defense proteins of carnauba tree (Copernicia cerifera) wax. Identification and partial characterization of a chitinase and a B-1,3glucanase. Plant Physiology and Biochemistry 40:11-16.

DAVE, Y., KURIACHEN, P.M. \& THOMAS, V. 1988. Development, structure and senescence of colleters in Gardenia lucida Roxb. (Rubiaceae). Acta Societatis Botanicorum Poloniae 57:3-7.

DELL, B. 1977. Distribution and function of resin and glandular hairs in Western Australian Plants. Journal of Proceedings of the Royal Society of Western Australia 59:119-123.

DURKEE,L.T.,BAIRD,C.W.\&COHEN,P.F. 1984.Lightand electron microscopy of the resin glands of Passiflora foetida (Passifloraceae). American Journal of Botany 71:596-602.

FAHN, A. 1979. Secretory tissues in plants. Academic Press, London.

FAHN, A. 1990. Plant anatomy. Pergamon Press, Oxford.

FARRELL, B.D., DUSSOURD, D.E. \& MITTER, C. 1991. Escalation of plant defense: do latex and resin canals spur plant diversification? American Naturalist 138:881-900.

FRANCO, A.C. 2002. Ecophysiology of woody plants. In The cerrados of Brazil: ecology and natural history of a neotropical savanna (P.S. Oliveira \& R.J. Marquis, eds.). Columbia University Press, New York, p.178-197.

GERLACH, D. 1969. Botanische mikrotechnik. Georg Thieme Verlag, Stuttgart.

GERRITS, P.O. 1991. The application of glycol methacrylate in histotechnology; some fundamental principles. Department of Anatomy and Embryology. State University of Gröningen, Gröningen.

GUARIM NETO, G. 1985. Espécies frutíferas do cerrado matogrossense. Boletim FBCN (Fundação Brasileira para a Conservação da Natureza) 20:46-50.

HORNER, H.T. \& LERSTEN, N.R. 1968. Development, structure and function of secretory trichomes in Psychotria bacteriophila (Rubiaceae). American Journal of Botany 55:1089-1099. 
JAYAWEERA, D.M.A. 1963a. The rubiaceous genus Mussaenda: the morphology of the Asian species. Journal of the Arnold Arboretum 44:111-126.

JAYAWEERA, D.M.A. 1963b. The rubiaceous genus Mussaenda: the species of India and Ceylon. Journal of the Arnold Arboretum 44:232-267.

JAYAWEERA, D.M.A. 1964. The rubiaceous genus Mussaenda: the species of the Philippine Islands. Journal of the Arnold Arboretum 45:101-139.

JAYAWEERA, D.M.A. 1965. The rubiaceous genus Mussaenda: a new species from North Burma. Journal of the Arnold Arboretum 46:366-368.

JENSEN, W.A. 1962. Botanical histochemistry: principles and practice. W.H. Freeman, San Francisco.

JOHANSEN, D.A. 1940. Plant microtechnique. McGraw-Hill, New York.

JOHANSSON, J.T. 1987. Revision of the genus Prismatomeris Thw. (Rubiaceae, Morindeae). Opera Botanica 94:1-62.

KARNOVSKY, M.J. 1965. A formaldehyde-glutaraldehyde fixative in high osmolality for use in electron microscopy. Journal of Cell Biology 27:137A-138A.

KLEIN, D.E., GOMES, V.M., SILVA-NETO, S.J. \& DA CUNHA, M. 2004. The structure of colleters in several species of Simira (Rubiaceae). Annals of Botany 94:733-740.

KRONESTEDT-ROBARDS, E. \& ROBARDS, A. 1991. Exocytosis in gland cells. In Endocytosis, exocytosis and vesicle traffic in plants (C. Hawea, J. Coleman \& D. Evans, eds.). Cambridge University Press, Cambridge, p.199-232.

LANGENHEIM, J.H. 1994. Higher plant terpenoids: a phytocentric overview of their ecological roles. Journal of Chemical Ecology 20:1223-1280.

LANGENHEIM, J.H. 2003. Plant resins: chemistry, evolution, ecology and ethnobotany. Timber Press, Cambridge.

LERSTEN, N.R. 1974a. Morphology and distribution of colleters and crystals in relation to the taxonomy and bacterial leaf nodule symbiosis of Psychotria (Rubiaceae). American Journal of Botany 61:973-981.

LERSTEN, N.R. 1974b. Colleter morphology in Pavetta, Neorosea and Tricalysia (Rubiaceae) and its relationship to the bacterial leaf nodule symbiosis. Botanical Journal of Linnean Society 69:125-136.

LERSTEN, N.R. 1975. Colleter types in Rubiaceae, especially in relation to the bacterial leaf nodule symbiosis. Botanical Journal of Linnean Society 71:311-319.

LERSTEN, N.R. \& HORNER, H.T. 1967. Development and structure of bacterial leaf nodules in Psychotria bacteriophila Val. (Rubiaceae). Journal of Bacteriology 94:2027-2036.

MANGALAN, S., KURIEN, K.P., JOHN, P. \& NAIR, G.M. 1990. Development, structure and cytochemistry of resinsecreting colleters of Gardenia gummifera (Rubiaceae). Annals of Botany 66:123-132.

MAZIA, D., BREWER, P.A. \& ALFERT, M. 1953. The cytochemical staining and measurement of protein with mercuric bromophenol blue. The Biological Bulletin 104:57-67.
MILLER, I.M., SCOTT, A. \& GARDNER, I.C. 1983. The development, structure and function of dendroid colleters in Psychotria kirkii Hiern (Rubiaceae). Annals of Botany 51:621-630.

O'BRIEN, T.P., FEDER, N.\&MCCULLY,M.E. 1965. Polychromatic staining of plant cell walls by toluidine blue O. Protoplasma 59:368-373.

PEARSE, A.G.E. 1980. Histochemistry, theoretical and applied: preparative and optical technology. $4^{\text {th }}$ ed. Churchill Livingston, Edinburgh.

RAMAYYA, N. \& BAHADUR, B. 1968. Morphology of the "squamellae" in the light of their ontogeny. Current Science 37:520-522.

ROBBRECHT, E. 1978. Sericanthe, a new African genus of Rubiaceae (Coffeeae). Bulletin van Nationale Plantentuin van Belgie 48:3-78.

ROBBRECHT, E. 1983. The African genus Tricalysia A. Rich. (Rubiaceae) 3. Probletostemon revived as a section of subgenus Tricalysia. Bulletin van Nationale Plantentuin van Belgie 53:299-320.

ROBBRECHT, E. 1987. The African genus Tricalysia A. Rich. (Rubiaceae). 4. A revision of the species of section Tricalysia and section Rosea. Bulletin van Nationale Plantentuin van Belgie 57:39-208.

RODRIGUES, V.E.G. \& CARVALHO, D.A. 2001. Levantamento etnobotânico de plantas medicinais no domínio cerrado na Região do Alto Rio Grande - Minas Gerais. Ciência e Agrotecnologia 25:102-123.

SOLEREDER, H. 1908. Systematic anatomy of the dicotyledons. Clarendon Press, Oxford.

SUBRAMANIAN, R.B., MURUGAN, V., MOHAN, J.S.S. \& INAMDAR, J.A. 1989. Optical microscopic studies on the structure and secretion of resin glands in some Apocynaceae. Proceedings of the Indian Academy of Sciences (Plant Sciences) 99:423-429.

THOMAS, V. 1991. Structural, functional and phylogenetic aspects of the colleter. Annals of Botany 68:287-305.

THOMAS, V. \& DAVE, Y. 1989a. Structure, origin, development and senescence of colleters in Nerium indicum Mill. ( $N$. odorum Soland., Apocynaceae). Korean Journal of Botany 32:163-172.

THOMAS, V.\& DAVE, Y. 1989b. Histochemistry and senescence of colleters of Allamanda cathartica (Apocynaceae). Annals of Botany 64:201-203.

THOMAS, V.\&DAVE, Y. 1989c. The colleters of Alstonia scholaris L. (Apocynaceae). Indian Botanical Contactor 6:25-29.

THOMAS, V. \& DAVE, Y. 1990. Structure and necrosis of stipular colleters in Mitragyna parvifolia (Rubiaceae). Belgian Journal of Botany 123:67-72.

THOMAS, V., DAVE, Y. \& MENON, A.R.S. 1989. Anatomy and histochemistry of colleters in Roupelia grata Wall. (Apocynaceae). Nordic Journal of Botany 8:493-496.

VAN HOVE, C. 1972. Structure and initiation of nodules in the leaves of Neorosea andongensis (Hiern) N. Hallé. Annals of Botany 36:259-262. 
VAN HOVE, C. \& KAGOYRE, K. 1974. A comparative study of stipular glands in nodulating and non-nodulating species of Rubiaceae. Annals of Botany 38:989-991.

WOODSON, R.E. \& MOORE, J.A. 1938. The vascular anatomy and comparative morphology of the Apocynaceous flowers. Bulletin of the Torrey Botanical Club 65:135-165.
ZALUCKI, M.P., BROWER, L.P. \& ALONSO, A. 2001. Detrimental effects of latex and cardiac glycosides on survival and growth on first-instar monarch butterfly larvae Danaus plexippus feeding on the sandhill milkweed Asclepias humistrata. Ecological Entomology 26:212-224. 